\title{
Estimating the water and heat budget as an indicator for water resources management using an integrated watershed modeling tool
}

\author{
$\underline{\text { Yasuhiro Tawara }}^{\text {a }}$, Aurelien Hazart a ${ }^{\text {, Koji Mori a }}{ }^{\text {, Kazuhiro Tada a }}{ }^{\text {, Junya Takeshima }}{ }^{\text {b }}$ \\ Shoichi Nishiyama ${ }^{b}$, Ahmad Al-Hanbali ${ }^{a}$ and Hiroyuki Tosaka ${ }^{c}$ \\ ${ }^{a}$ Geosphere Environmental Technology Corporation \\ ${ }^{b}$ Oyo Corporation \\ ${ }^{c}$ The University of Tokyo \\ Email:tawara@getc.co.jp
}

\begin{abstract}
A water resources management considering not only water but also heat has become a crucial issue due to limited availability of water resources, increasing water contaminations and ground source heat utilizations. Indicators are useful to manage water resources. Water budget and Heat budget can be one of the major indicators for sustainable water resources management because detecting the disequilibrium of these budgets at an early stage makes it possible to implement effective measures.

However, many components required to estimate these budgets in a domain that include the surface and the subsurface are difficult to measure directly, for instance, the water and heat transported by recharge, and the groundwater discharge in a regional watershed scale.
\end{abstract}

An integrated watershed modeling technique allows to represent seamlessly the mass and heat transport behaviors from the surface to the underground in arbitrary temporal and spatial scales. Moreover, a spatiotemporal water flow behavior can be expressed without any explicit conditions for routing the paths of water movement. Therefore, this kind of modeling technique becomes efficient tool to estimate the components of these budgets.

First, the framework for estimating these budgets using an integrated watershed modeling tool is proposed in this study as follows:

- Collecting available data such as meteorology/ocean conditions, land use/land cover, topography, soil/geology, water use/heat utilization and monitoring data

- Associating these data with model parameters like porosity, heat conductivity and rainfall conditions

- Model construction by assigning parameters to each discretized mesh and calibration through comparison with monitoring data

- Estimating the water and heat budget

Then, the water and heat budget components which are classified into inflow and outflow for the surface and the subsurface domains are described. Additionally, the following applications to estimating the components of the water and heat budget using actual watershed models in various scales are presented briefly:

- Estimation of the recharge rate of whole Japan using a national-scale watershed model

- Water budget estimation using regional-scale watershed models

- Feasibility study of ground source heat utilization in a local-scale urban area

In order to perform the water and heat budget estimations more rapidly and with minimal cost, the authors are challenging the development of new data models updated continuously and re-used efficiently. The challenge in this domain is to provide information immediately to help the decision-making for watershed management.

Keywords: Aater and heat budget, indicator, water resources management, integrated watershed modeling, GETFLOWS 
Tawara et al., Estimating the water and heat budget as an indicator for water resources management using an integrated watershed modeling tool

\section{INTRODUCTION}

Securing water resources has become of great interest to scientists and governments due to limited availability of water resources, water contaminations and climate change. Limited water resources exist in many countries, especially those located in arid and semi-arid regions. Also, groundwater contaminations by nitrate nitrogen, which derive from increasing the amount of fertilization for food production since the 1970s and improper handling of livestock manure have become obvious in various parts of the world (e.g., Ghaly et al., 2015). Therefore, an urgent response to manage water quantity and quality is required. In Japan, the use of renewable energy is promoted, especially after the Fukushima Daiichi nuclear power plant accident that followed the Great East Japan Earthquake. A ground source heat (GSH) energy is one of the potential renewable energy and it can be utilized efficiently due to fast groundwater velocity in Japan. The assessments of temperature change induced by GSH utilization and the selections of suitable sites have been conducted in a number of research institutions. Thus, a water resources management considering not only water but also heat has become a crucial issue.

Indicators are useful to manage water resources; therefore, various research studies have tried to develop such practical indicators (e.g., Amber et al., 2011). Water budget and Heat budget (WB-HB) can be one of the major indicators for water resources management. Detecting the disequilibrium of WB-HB at an early stage makes it possible to implement effective measures.

However, many components required to estimate the WB-HB in a domain that include the surface and the subsurface cannot be observed easily, for instance, the water and heat transported by recharge, and the groundwater discharge in a regional watershed scale. This might explain why the number of studies aiming to estimate the WB-HB is rather limited in the literatures.

To overcome these difficulties, we propose a WB-HB estimation framework based on integrated watershed modeling techniques. This approach differs from the traditional disconnection-reconnection approach (see the following section for a brief comparison of both approaches). By coupling surface and subsurface fluids flow, mass and heat transport processes with complex meteorological conditions, land use/land cover and human activities such as irrigation and groundwater pumping, they can become efficient tools to estimate the components of the WB-HB. Moreover, the spatiotemporal water flow can be estimated without any explicit prior specification for routing the pathways of water movement.

First, the framework of estimating the WB-HB using an integrated watershed modeling tool and the WB-HB components are described. Then, some applications to estimate the components of the WB-HB are briefly presented. The model used in these applications can consider simultaneous transport processes of fluids (water, air), various other materials and heat, and estimate the WB-HB in various scales actual watersheds. In the last section, some limitations of this approach and perspectives of improvement are listed.

\section{METHOD OF WATER AND HEAT BUDGET ESTIMATION}

\subsection{Integrated watershed modeling}

Various methods to model actual watersheds have been proposed. They usually include a module for WB estimation (e.g., DHI, 2007). Most of them adopt an approach where the targeted watershed is divided into several components such as river, slope, unsaturated/saturated zone in underground with each component being predefined during the modelization stage. The budget calculations are estimated within each component and then, all components are reconnected using empirical parameters. In this disconnectionreconnection approach, it is usually necessary to specify several paths of fluid movement in the watershed, so even calibrated models require attentions when applied to different time and spatial scales (Mori et al., 2015). Another approach is to consider an integrated watershed model where transport processes of water, various other materials and heat are treated simultaneously. In such methods, the paths of the fluid movement are not specified in advance but naturally estimated during the simulation. To demonstrate the efficiency of this approach, the integrated watershed modeling system GETFLOWS (GEneral-purpose Terrestrial fluid FLOW Simulator) described in Tosaka et al. (2000) and Mori et al. (2015) is used in this study. This model allows to represent seamlessly the mass and heat transport behaviors from the surface to the underground in arbitrary temporal and spatial scales. The main physicochemical processes considered in this system are as follows:

- Hydrological processes at land surface (rainfall, snowfall, snow melting, rainfall interception, solar radiation, evapotranspiration, latent heat and sensible heat transfer, erosion, deposition, tidal change, etc.)

- Isothermal and non-isothermal fluid flow in surface and subsurface

- Mass and heat transport between surface and subsurface (surface water/groundwater interaction) 
Tawara et al., Estimating the water and heat budget as an indicator for water resources management using an integrated watershed modeling tool

- Mass transport in aqueous and gas phase (advection, dispersion, diffusion, radioactive decay, etc.)

- Phase transfer (dissolution, volatilization, sorption, etc.)

- Condensation and evaporation of water

- Erosion, deposition and transport of sediments composed of mixed grain size

- Elevation changes by erosion and deposition

- Heat transport (advection, conduction) and heat exchange between the different phases

- Human activities such as groundwater pumping, river water intake, irrigation and dam operation.

The equations governing the transport of water, air, various other materials and heat are based on mass or energy balance laws. The fluid velocities in the governing equations are calculated from Darcy's law except for surface water velocity which is based on the mean velocity formula calculated from the linearized diffusion-wave approximation to open-channel flow (Tosaka et al., 2000). Surface water/groundwater interactions such as recharge and discharge are expressed naturally by introducing pseudo functions to capillary pressure and relative permeability used for evaluating hydraulic potential gradient and transmissibility (Tosaka et al., 2000).

The governing equations are discretized spatially by the integral finite difference method (IFDM) and temporally by the fully implicit method. Because of the strong nonlinearity of the governing equations, they are iteratively converged using the Newton-Raphson method. More details regarding the numerical solution procedure can be found in Mori et al. (2015).

\subsection{Framework for estimating water and heat budget}

The first step of a WB-HB estimation workflow is to collect available data. These data are usually categorized as follow: meteorological/ocean conditions, land use/land cover, topography, soil/geology, water use/heat utilization and monitoring data representing the actual watershed. These data are interpolated spatially and temporally, and associated with the model parameters like the porosity, the heat conductivity and the rainfall conditions. Then, a watershed model is constructed by assigning these parameters to each discretized mesh. The models are classified into three types depending on their scale: national, regional and local. Each scale model can be considered independently or in relation with the other scale models from which it can get and send data such as initial conditions, boundary conditions and qualified parameters between different models. Finally, the calibrated model is used to estimate the WB-HB. A schematic view of the estimating WB-HB framework is presented in Figure 1.

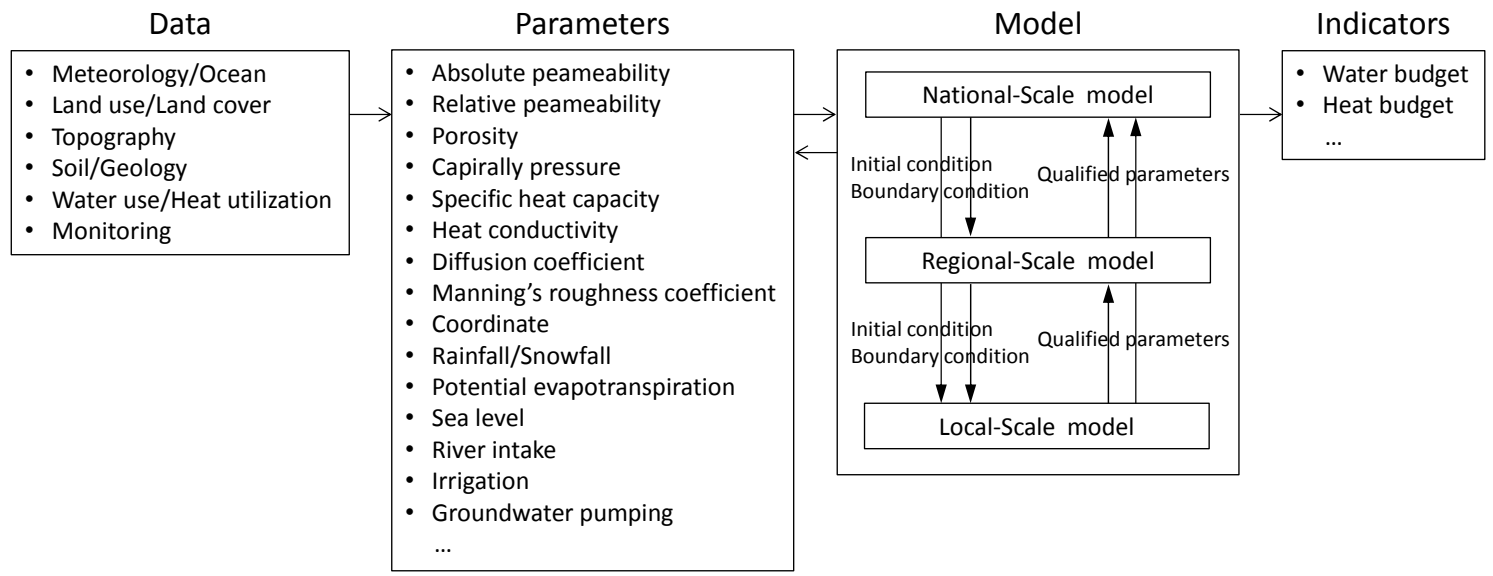

Figure 1. Framework for estimating WB-HB

\subsection{Water and heat budget components}

The flow of fluid movement is grouped into components for the purpose of estimating the WB-HB. The components at the watershed scale are listed in Table 1. They are classified into inflow and outflow components for the surface and the underground domains.

Water and heat supplied from rainfall, surface flow, groundwater flow and outside of targeting area by human activities are included in the inflow components at the surface. The outflow components at the surface are water and heat drained by evaporation, transpiration, surface flow, groundwater flow and human activities to outside of targeting area. 
Tawara et al., Estimating the water and heat budget as an indicator for water resources management using an integrated watershed modeling tool

Table 1. WB-HB components at a watershed scale.

\begin{tabular}{|c|c|c|}
\hline & Surface & Underground \\
\hline \multirow[t]{4}{*}{ Inflow } & (a) Rainfall & (e) Surface water (Recharge) \\
\hline & (b) Surface water & (f) Groundwater \\
\hline & (c) Groundwater (Spring) & (g) Human activities \\
\hline & (d) Human activities & \\
\hline \multirow[t]{4}{*}{ Outflow } & (h) Evapotranspiration & (1) Soil evaporation \\
\hline & (i) Surface water & (m) Surface water (Spring) \\
\hline & (j) Groundwater (Recharge) & (n) Groundwater \\
\hline & (k) Human activities & (o) Human activities \\
\hline
\end{tabular}

In the underground area, water and heat supplied or drained due to surface water, groundwater and human activities are classified as inflow and outflow components. Evaporation from topsoil is added as outflow components.

Note that the inflow from the groundwater at the surface (component c) is the opposite of the outflow from the underground to the surface (component $\mathrm{m}$ ). Similarly, the outflow from the surface to the underground (component $\mathrm{j}$ ) is the opposite of the inflow from the surface water in the underground (component e). Both pair $(\mathrm{c}, \mathrm{j}$ and $\mathrm{e}, \mathrm{m})$ represents the amount of recharge and discharge through the land surface.

\section{APPLICATIONS}

\subsection{Estimation of the recharge rate using a national-scale watershed model}

This application focuses on the estimation of one of the WB components, the groundwater recharge rate, at a country-scale. The presented results belong to a wider study that aims providing timely information to help decision-making and action for watershed management. By updating regularly the meteorological conditions, the human activities and to some extend the hydro-geological properties on a large-scale model, the water resources condition can be tracked and used to produce indicators of flow variations over the years. Computing the groundwater recharge rate, as a part of the WB, participates to the elaboration of such indicators. The average recharge rate is estimated here on a three-dimensional, national-scale watershed model covering the major land and adjacent sea of whole Japan $\left(770,000 \mathrm{~km}^{2}\right)$. The horizontal resolution of this model is $500 \mathrm{~m}$ and the vertical resolution varies from $1 \mathrm{~m}$ to $500 \mathrm{~m}$ depending on the elevation. Up-todate data of meteorological conditions, land use/land cover, terrain and geology over the 30 years period are used. The three-dimensional hydrogeological structure is based on the Seamless Digital Geological Map of Japan $(1: 200,000)$ which is the product of the merged 1:200,000 geologic quadrangle maps covering the entire country of Japan by the National Institute of Advanced Industrial Science and Technology. Hydraulic and thermal properties such as permeability and heat capacity are deduced empirically from existing studies. At the moment, no parameter calibration is conducted (calibration will be done in a future study). Calculation of water, air, salinity and heat transport processes are carried out simultaneously to obtain the groundwater

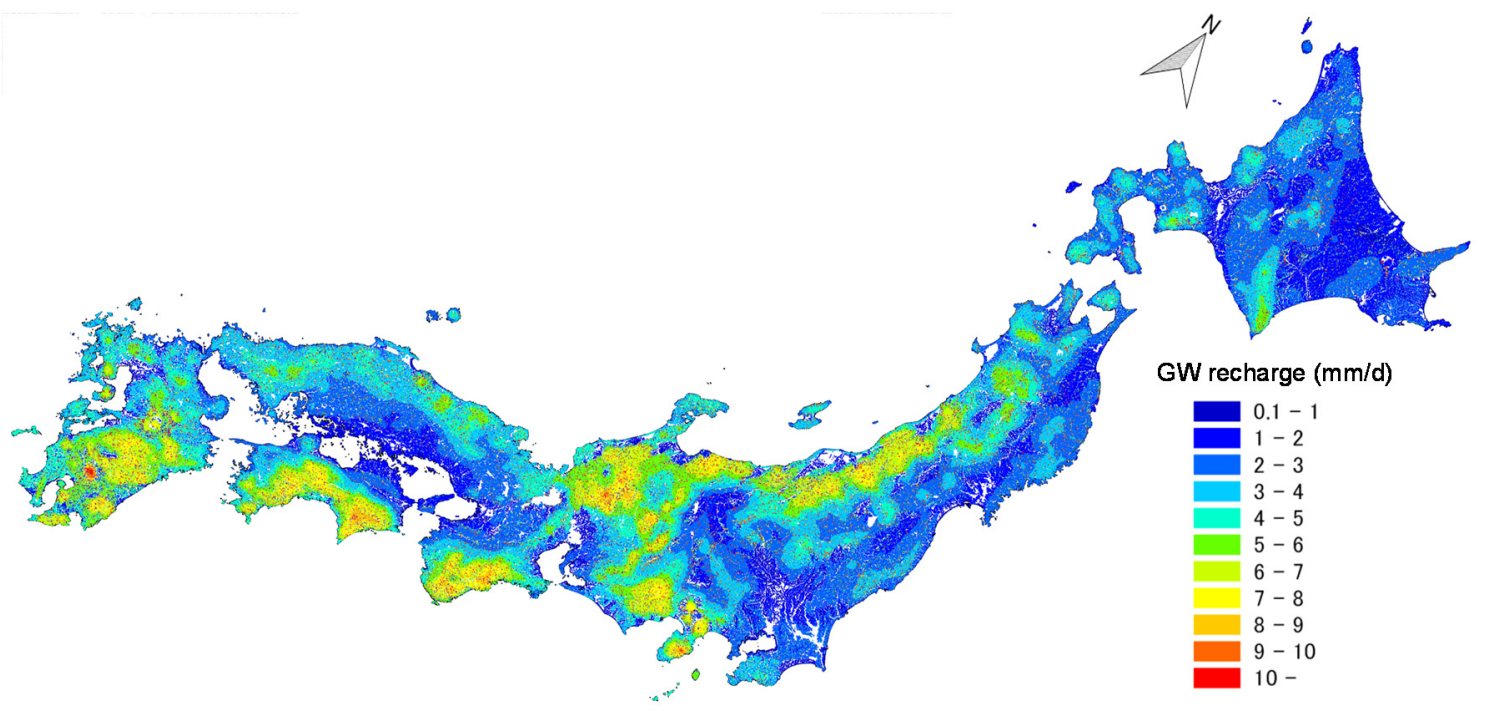

Figure 2. Average recharge rate distribution in whole Japan (1981-2010). 
Tawara et al., Estimating the water and heat budget as an indicator for water resources management using an integrated watershed modeling tool

recharge rate of the 30 years average state shown in Figure 2. The recharge rate is defined as the surface water flow through the land surface interface. Yearly average of weather data over the 30 years period is used to produce the map where the recharge rate greater than $0.1 \mathrm{~mm}$ per day is represented. Blank area represents the rate lower than $0.1 \mathrm{~mm}$ per day or the groundwater discharge area. This recharge rate distribution is consistent with the spatial distribution of rainfall (not shown here).

\subsection{Water budget estimation using regional-scale watershed model}

Some applications using an integrated watershed modeling approach to estimate the WB at a regional-scale are presented, with a focus on the Shigenobu-river watershed. The Shigenobu-river is one of the primary rivers in Ehime Prefecture, Japan. It is $36 \mathrm{~km}$ long and cover a watershed area of $445 \mathrm{~km}^{2}$. Whole Shigenoburiver watershed is considered in this calculation. The three-dimensional model has a horizontal resolution from $50 \mathrm{~m}$ to $500 \mathrm{~m}$ and a vertical resolution from $0.3 \mathrm{~m}$ to $500 \mathrm{~m}$ depending on the elevation and is represented in Figure 3a. Public data are collected to compose the required data for the modeling: meteorological conditions using observed data, land use/land cover, terrain and water use. Topsoil, quaternary sediments consists of gravel, coarse sand, medium sand, fine sand, silt and clay, and impermeable bedrock are considered following the geological classifications proposed in some literatures. Hydraulic conductivity and porosity of topsoil, quaternary sediments are identified during calibration by trial and error through comparison with river flow rate observed at four points and groundwater level observed at two points. The some of the results well reproduced river discharge and groundwater level are shown in Figure $3 \mathrm{~b}$.

It corresponds to a transient calculation using monthly rainfall and evapotranspiration from 1975 to 2005.
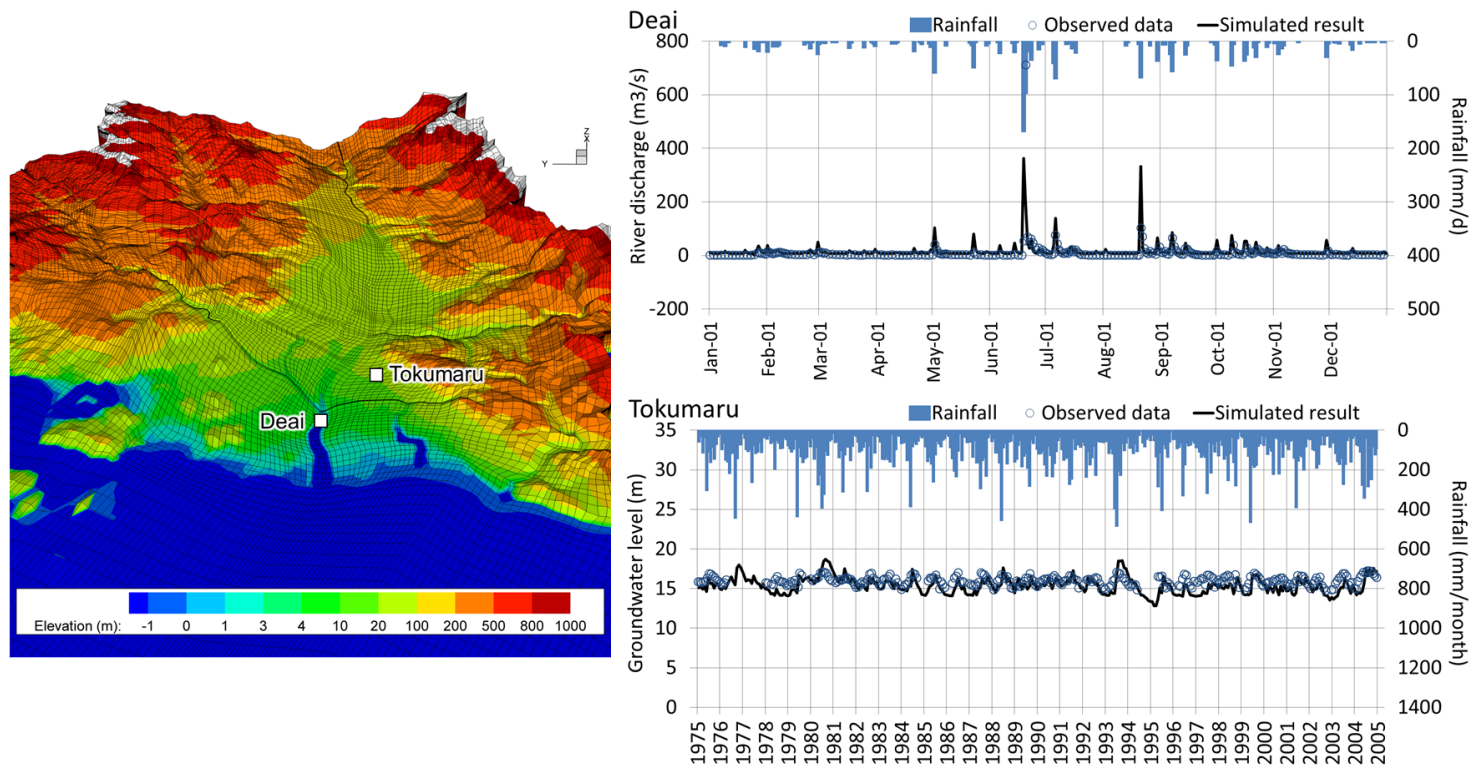

Figure 3. (a)Shigenobu-river watershed model, (b) Comparison of observed data and simulated results.

Averaged WB components during calculation period for topsoil and quaternary sediments are extracted from this calculation results and shown in Table 2 . According to this result, about $44 \%$ of water supplied to the watershed by rainfall return to the atmosphere by evapotranspiration (component $h, 1)$. About $58 \%$ of rainfall infiltrates through the land surface (component $\mathrm{j}, \mathrm{e}$ ). The amount of groundwater flowing out to sea is about $1.4 \%$ of the rainfall (component $\mathrm{n}$ ). The amount of inflow in subsurface is slightly less than the outflow was shown in this study.

Other usages of integrated watershed modeling techniques for WB calculation was presented in Hazart et al.(2014) for the Hadano basin, near Tokyo. In this region, the water resources used by city water department and industries are mainly supplied by groundwater. In the Hadano basin study, a three-dimensional watershed model was built to reproduce a large number of groundwater level data measured for a long period. Then, several surrogate models are trained to fit the WB components with direct observations as input data (river flow rate, groundwater

Table 2. WB in Shigenobu-river basin.

\begin{tabular}{cll}
\hline & Surface & \multicolumn{1}{c}{ Subsurface } \\
\hline \hline Inflow & (a) 289 & (e) 168 \\
$\left(10^{6} \mathrm{~m}^{3} / \mathrm{yr}\right)$ & (b) 210 & (f) 25 \\
& (c) 115 & (g) 0 \\
& (d) 0 & \\
\hline Outflow & (h) 86 & (l) 42 \\
$\left(10^{6} \mathrm{~m}^{3} / \mathrm{yr}\right)$ & (i) 361 & (m) 115 \\
& (j) 168 & (n) 4 \\
& (k) 0 & (o) 39 \\
\hline
\end{tabular}


Tawara et al., Estimating the water and heat budget as an indicator for water resources management using an integrated watershed modeling tool

level). The purpose is to quickly estimate the WB of the watershed when new observations are made without resorting on the time-consuming execution of the physical model. This system also simplifies the workflow by removing the need of watershed modeling skills for monitoring the managed area. Not only modeling studies but also field researches are conducted continually in a feedback loop to improve the accuracy of the estimated WB in this region.

\subsection{Feasibility study of ground source heat utilization in local-scale urban area}

A feasibility study assuming GSH utilization in central Tokyo area is conducted using a high resolution model (horizontal resolution of $15 \mathrm{~m}$ ) at a local-scale. Up-to-date public databases are used for the meteorological conditions, land use/land cover, terrain and water use. First, a geological model of horizontal resolution of $25 \mathrm{~m}$ based on about 1,500 boring data is used to build the local-scale watershed model. The numerical computation considers non-isothermal water and air transport in both surface and subsurface. This model is validated by comparing the obtained results with observations of groundwater level (29 points) and groundwater temperature (5 points). Hydraulic conductivity, porosity, heat capacity and thermal conductivity of shallow aquifer (four parameters per geological layer) are identified through trial and error calibrations. Simulated groundwater level and temperature are good agreement with observed data and one of the reproduced groundwater temperature are shown in figure 4. The calculation settings of this case study are as follows:

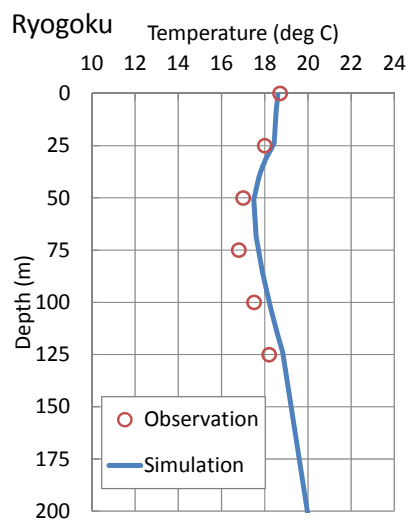

Figure 4. Reproduction of groundwater temperature.

- $70 \%$ of electricity consumed as cooling and heating in three city blocks of central Tokyo (Kasumigaseki 1 , 2, 3-chome) is produced by GSH energy.

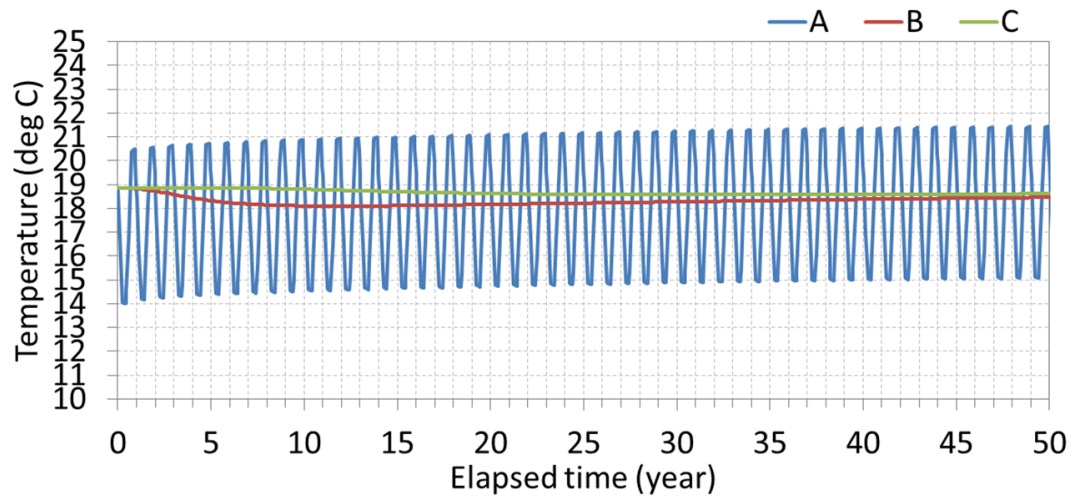

Figure 5. Groundwater temperature evolution at point A, B and C after the GSH utilization started.
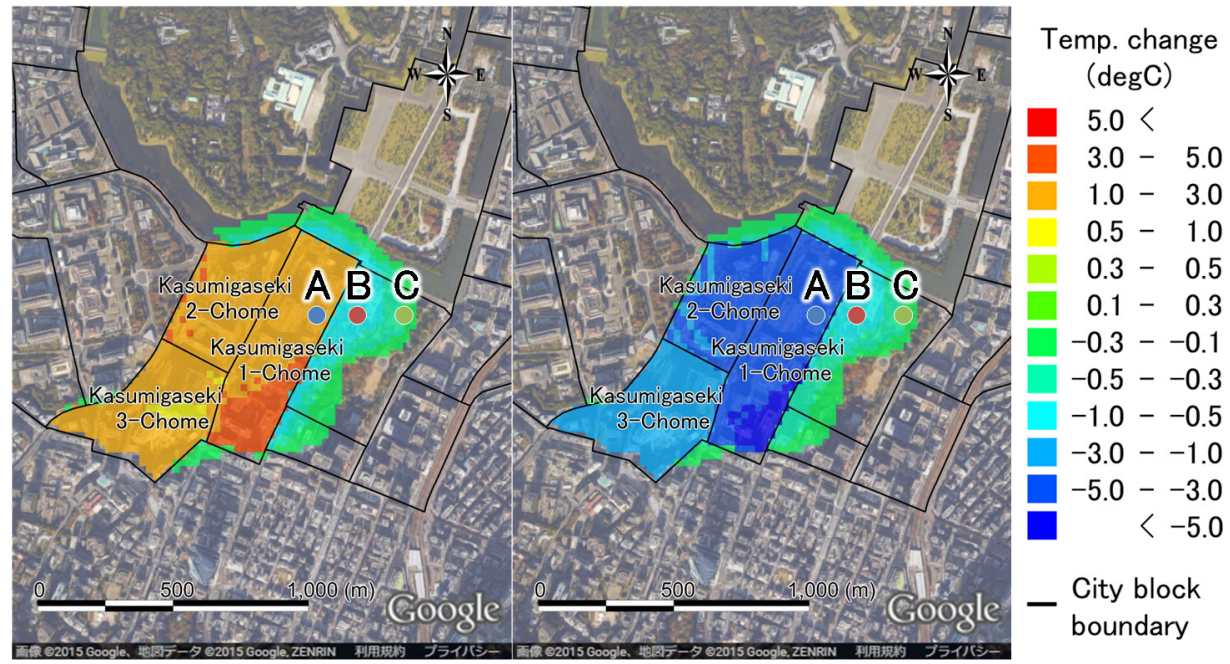

- City block

Figure 6. Distributions of underground temperature change at $100 \mathrm{~m}$ depth in summer (left) and winter (right) after 20 years. 
Tawara et al., Estimating the water and heat budget as an indicator for water resources management using an integrated watershed modeling tool

- GSH operation is conducted at a depth of $100 \mathrm{~m}$

- Heat is evenly injected into underground of this three blocks in summer and drained from underground in winter repeatedly during 50 years

Figure 5 shows the time evolution of the groundwater temperature at three evaluation points (marked A, B and $\mathrm{C}$ in Figure 6) for 50 years from the start of GSH utilization. The evaluation points A is close to GSH operation area and the points $B$ and $C$ are respectively $100 \mathrm{~m}$ and $250 \mathrm{~m}$ away from that area to the downstream side. The underground temperature at point $\mathrm{A}$ changes the order of $6 \operatorname{deg} \mathrm{C}$ in a year due to the GSH operations. The underground temperature at point $\mathrm{B}$ and $\mathrm{C}$ remains almost the same without responding to the GSH operations. These results indicate that the GSH utilization does not induce disequilibrium of the HB significantly. Additionally, the distributions of underground temperature change at $100 \mathrm{~m}$ depth in summer and winter after 20 years in Figure 6 show that the impact to the surrounding temperature environment is very limited.

\section{CONCLUSIONS AND FUTURE WORK}

A framework for estimating the WB-HB using an integrated watershed modeling technique was proposed in this study and applications of the WB-HB estimation using actual watershed models in various scales were presented. The accuracy of the estimation was qualitatively validated by experts of each watershed. It was shown that all components of the WB can be estimated appropriately using validated watershed models. Additionally, the approach is applicable to detect the disequilibrium of the HB, as shown in the GSH utilization study. Compared to the disconnection-reconnection approach where each component is treated separately and then empirically grouped, this approach based on the integrated watershed modeling allows a global incorporation of the complicated processed in the watershed.

However, the WB-HB estimation by watershed modeling is still an expensive work at the moment owing to time-consuming tasks such as collecting the data and building and calibrating the $3 \mathrm{D}$ model. In order to perform the WB-HB estimation more rapidly and with minimal cost, the authors are challenging the development of new data models. In these data model, all the data required in the watershed modeling along with their meta-data (location in space and time, etc.) would be updated continuously and re-used efficiently. Consequently, an analysis model of any resolution could be extracted quickly after a study area is determined. Additionally, the data model could be updated by incorporating information of the watershed achieved through modeling and field studies in a feedback loop. The challenge in this domain is to provide information immediately to help the decision-making for watershed management.

\section{ACKNOWLEDGMENTS}

This study includes a part of the results of 'Feasibility Study on Large-Scale Ground Source Heat Energy Potential in Megacity' which is funded by New Energy and Industrial Technology Development Organization of Japan.

\section{REFERENCES}

Amber B. and Marty D.M. (2011). A Review of Water Scarcity Indices and Methodologies, The Sustainability Consortium, White Paper \#106.

Danish Hydraulic Institute (2007). MIKE SHE USER MANUAL, VOLUME 2: REFERENCE GUIDE.

Ghaly A.E. and Ramakrishnan V.V. (2015). Nitrogen Sources and Cycling in the Ecosystem and its Role in Air, Water and Soil Pollution: A Critical Review, Journal of Polluttion Effects \& Control, 3: 136. doi: $10.4172 / 2375-4397.1000136$

Hazart A., Mori K., Tada K. and Tosaka H. (2014). Using surrogate modeling for fast estimation of water budget component in a regional watershed, Intl. Env. Modelling and Software Society (iEMSs) 7 th Intl. Congress on Env. Modelling and Software, San Diego, CA, USA, Proceedings, Volume 3, 1583-1590. (http://www.iemss.org/sites/iemss2014/ proceedings.php)

Mori K., Tada K., Tawara Y., Ohno K., Asami M., Kosaka K., Tosaka H. (2015). Integrated watershed modeling for simulation of spatiotemporal redistribution of post-fallout radionuclides: Application in radiocesium fate and transport processes derived from the Fukushima accidents, Environmental Modelling \& Software, 72, 126-146.

Tosaka H., Ito K. and Furuno T. (2000). Fully Coupled Formulation of Surface flow with 2-Phase Subsurface Flow for Hydorological Simulation, Hydrological Processes, 14 (3), 449-464. 